\title{
The growth of InGaAsP by CBE for SCH quantum well lasers operating at 1.55 and $1.4 \mu \mathrm{m}$
}

\author{
M.E. Sherwin, G.O. Munns, D.T. Nichols, P.K. Bhattacharya and F.L. Terry, Jr. \\ Center for High Frequency Microelectronics, Electrical Engineering and Computer Science Department, 2435 EECS Building, \\ The Unicersity of Michigan, Ann Arbor, Michigan 48109-2122, USA
}

\begin{abstract}
InGaAsP has been grown by CBE at compositions of $1.1,1.2$ and $1.4 \mu \mathrm{m}$ for the development of MQW-SCH lasers. The observed incorporation coefficients for TMI and TEG show strong temperature sensitivity while the phosphorus and arsenic incorporation behavior is constant over the substrate temperature range explored, 530 to $580^{\circ} \mathrm{C}$ setpoint. For higher substrate temperatures the growth rate increases with the largest growth rates occurring for the $1.4 \mu \mathrm{m}$ quaternary. Low temperature photoluminescence indicates the possibility of compositional grading or clustering for the $1.1 \mu \mathrm{m}$ material and also for the $1.2 \mu \mathrm{m}$ material grown at the lowest substrate temperature. The final laser structure was grown with the InP cladding regions grown at $580^{\circ} \mathrm{C}$ with the inner cladding and active regions grown at $555^{\circ} \mathrm{C}$. Using this approach we have successfully grown MQW-SCH lasers with the composition of the active In, $\mathrm{Ga}_{1}$... As ranging from $x=0.33$ to $x=0.73$. Threshold current densities as low as 689 A $/ \mathrm{cm}^{2}$ have been measured for an $800 \mu \mathrm{m} \times 90 \mu \mathrm{m}$ broad arca device with $x=0.68$.
\end{abstract}

\section{Introduction}

Recently, chemical beam epitaxy (CBE) has attracted attention for the growth of InP based lasers [1,2]. Much of this arises from the ability of CBE to produce high quality phosphorus containing layer with monolayer precision [3]. We have previously undertaken a study to optimise the growth of InP and InGaAs [4], and from this we have found that the InP is very sensitive to growth conditions while the InGaAs has a much larger window in parameter space where acceptable layers can be grown. The main limitation on InP is the substrate temperature, which is now fixed at $530^{\circ} \mathrm{C}\left(580^{\circ} \mathrm{C}\right.$ setpoint $)$. The objective of this study is to define the conditions at which we can grow good InGaAsP for InP based lasers.

All of the experiments carried out in this study were performed using a first generation Varian Gen II CBE reactor. Source materials used were TMI, TEG, $100 \% \mathrm{AsH}_{3}$ and $100 \% \mathrm{PH}_{3}$. Substrates were indium bonded to silicon wafers. We estimate that the actual substrate temperature is $50^{\circ} \mathrm{C}$ colder than thermocouple setpoint [5], and all growth temperatures reported in this study are setpoint. Previous work has indicated that layer thickness and composition uniformity are better than $1.5 \%$ over a 2 inch diameter wafer.

\section{Bulk layer growth}

A study had been previously undertaken to determine optimum growth conditions (substrate temperature, hydride injector temperature and $\mathrm{V} /$ III ratio) for both In $P$ and InGaAs [4]. The samples were optimised for highest $77 \mathrm{~K}$ mobility with acceptable morphology. Using the determined growth conditions, $T_{\text {sub }}=580^{\circ} \mathrm{C}$ and $T_{\text {inj }}=$ $894^{\circ} \mathrm{C}$, we have grown InGaAs with a $77 \mathrm{~K}$ Hall mobility of $67,000 \mathrm{~cm}^{2} / \mathrm{V} \cdot \mathrm{s}$ and InP with a $77 \mathrm{~K}$ Hall mobility of $37,000 \mathrm{~cm}^{2} / \mathrm{V} \cdot \mathrm{s}$. The InGaAs showed little dependence on growth conditions over the range investigated. The InP showed strong dependences on all three variables, requiring a compromise to be made between high mobility and acceptable morphology.

For the bulk growth of InGaAsP the group III total flow was held constant to 1.25 SCCM, the $\mathrm{V} / \mathrm{III}$ ratio was held constant to 20 and the 


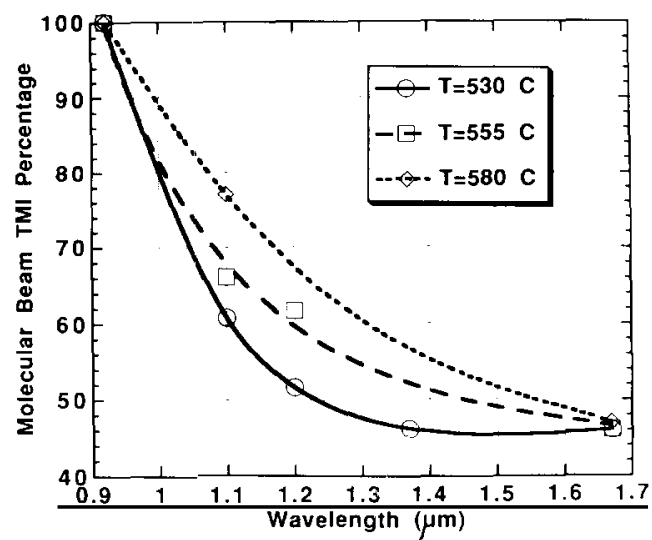

Fig. 1. Molecular beam concentration, TMI / TMI + TEG), needed for lattice matching as a function of temperature and desired wavelength. The dashed lines are only meant to show the trends.

substrate temperature was varied between 530 and $580^{\circ} \mathrm{C}$. For all conditions for which InGaAsP was successfully grown, lattice matching was achieved to better than $|\Delta a / a| \leq 1 \times 10^{-3}$. In GaAsP was grown at compositions corresponding to room temperature wavelengths of $1.1,1.2$ and $1.4 \mu \mathrm{m}$.

Fig. 1 shows the gas phase TMI concentration needed to achieve lattice matching as a function of temperature for InGaAsP. Over the temperature range explored the gas phase $\mathrm{PH}_{3}$ to $\mathrm{AsH}_{3}$ ratio was held constant for each composition.

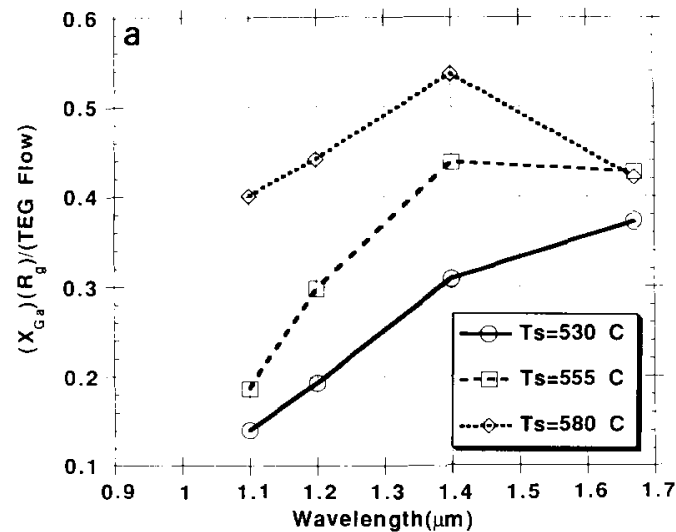

Fig. 2. (a) TEG incorporation coefficient for InGaAsP. (b) TMI incorporation coefficient for InGaAsP. The definition of the

incorporation coefficient is given in the text.

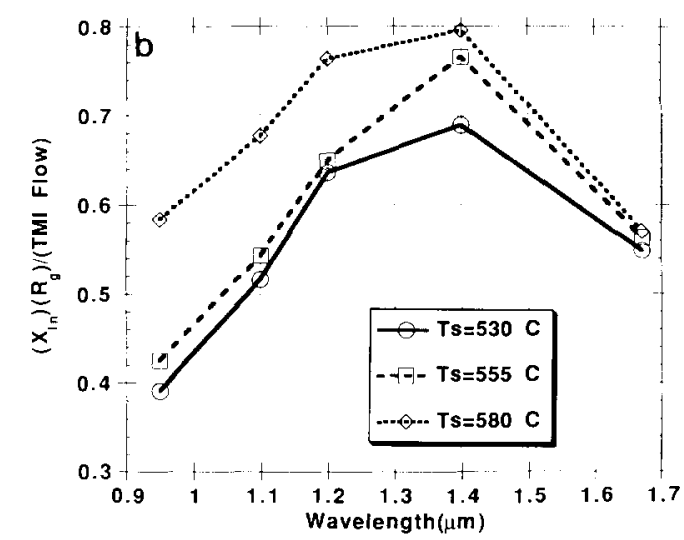

There was no noticeable difference in the $\mathrm{P}$ to As incorporation rates as a function of temperature. The lack of any temperature dependencies for the $\mathrm{P}$ to As incorporation rates is most likely due to the use of pre-cracked $\mathrm{AsH}_{3}$ and $\mathrm{PH}_{3}$ [2]. The 1.2 and $1.4 \mu \mathrm{m} \mathrm{InGaAsP}$ grown at $580^{\circ} \mathrm{C}$ and the $1.4 \mu \mathrm{m} \mathrm{InGaAsP}$ grown at $555^{\circ} \mathrm{C}$ show very broad $\mathrm{X}$-ray diffraction peaks and exhibited rough surfaces. These samples had larger growth rates than other compositions at the same substrate temperature, but lowering the total group III flow in an attempt to lower the growth rate did not improve the quality of the samples.

In order to further investigate the incorporation of TEG and TMI we have plotted the incorporation coefficients in figs. $2 a$ and $2 b$ as a function of composition and substrate temperature. The growth rate of the quaternary is controlled by the incorporation of both gallium and indium. The incorporation coefficient is defined as the total growth rate times the solid phase composition of the element (In or Ga) divided by the input gas flow rate of the precursor (TMI or TEG). As quoted, the coefficients are not normalized and merely provide a means for comparison. Combining figs. 1 and 2, a strong temperature dependence of both the TMI and TEG incorporation rates is evident, and an additional reduction in the TEG incorporation rate as the InGaAsP tends towards InP is also clearly shown. Other work with InGaAs and InGaP has also 
Table 1

$7 \mathrm{~K}$ photoluminescence results; the nominal compositions are at room temperature and the integrated intensities are for all peaks present and are in arbitrary units

\begin{tabular}{lllll}
\hline $\begin{array}{l}\text { Substrate } \\
\text { temperature } \\
\left({ }^{\circ} \mathrm{C}\right)\end{array}$ & $\begin{array}{l}\text { Nominal } \\
\text { composition } \\
(\mu \mathrm{m})\end{array}$ & $\begin{array}{l}\text { Peak } \\
\text { position } \\
(\mathrm{eV})\end{array}$ & $\begin{array}{l}\text { FWHM } \\
(\mathrm{meV})\end{array}$ & $\begin{array}{l}\text { Intensity } \\
(\mathrm{a} . \mathrm{u} .)\end{array}$ \\
\hline 530 & 1.1 & $\begin{array}{r}1.181 \\
1.192 \\
1.201\end{array}$ & $\begin{array}{r}30 \\
8\end{array}$ & 1.88 \\
& & 6 & \\
530 & 1.2 & 1.084 & 25 & 1.0 \\
& & 1.100 & 10 & \\
530 & 1.4 & 0.944 & 18 & 1.77 \\
555 & 1.1 & 1.205 & 20 & 2.12 \\
& & 1.208 & 9 & \\
555 & 1.2 & 1.216 & 7 & \\
580 & 1.1 & 1.219 & 11 & 4.23 \\
\hline
\end{tabular}

shown indium catalyzed TEG desorption and a dependence of $\mathrm{Ga}$ incorporation on phosphine flow $[6,7]$.

\section{InGaAsP photoluminescence and mobility}

Low temperature $(7 \mathrm{~K})$ photoluminescence was performed on the bulk InGaAsP layers using the $514.5 \mathrm{~nm}$ argon laser line, a $1.0 \mathrm{~m}$ spectrometer and conventional techniques. The laser power

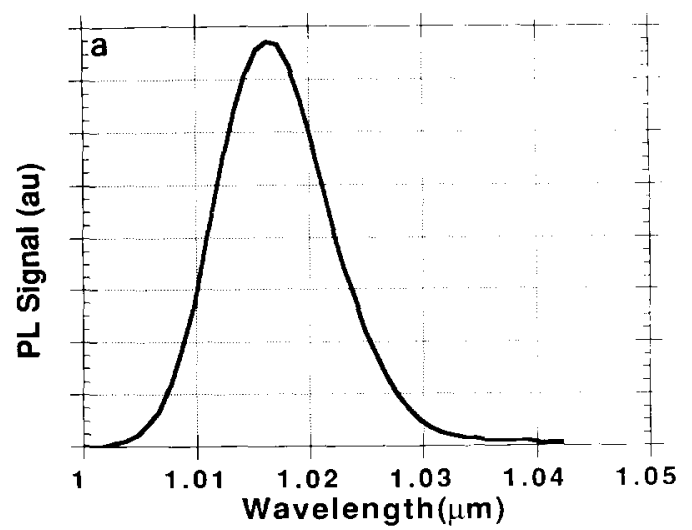

Table 2

Hall measurements on $1.1 \mu \mathrm{m}$ InGaAsP

\begin{tabular}{lllll}
\hline $\begin{array}{l}\text { Substrate } \\
\text { temperature } \\
\left({ }^{\circ} \mathrm{C}\right)\end{array}$ & $\begin{array}{l}n(300 \mathrm{~K}) \\
\left(\mathrm{cm}^{-3}\right)\end{array}$ & $\begin{array}{l}\mu(300 \mathrm{~K}) \\
\left(\mathrm{cm}^{2} / \mathrm{V} \cdot \mathrm{s}\right)\end{array}$ & $\begin{array}{l}n(77 \mathrm{~K}) \\
\left(\mathrm{cm}^{-3}\right)\end{array}$ & $\begin{array}{l}\mu(77 \mathrm{~K}) \\
\left(\mathrm{cm}^{2} / \mathrm{V} \cdot \mathrm{s}\right)\end{array}$ \\
\hline 540 & $3.5 \times 10^{16}$ & 1898 & $2.1 \times 10^{16}$ & 7831 \\
555 & $2.8 \times 10^{16}$ & 2305 & $1.8 \times 10^{161}$ & 10178 \\
580 & $8.9 \times 10^{16}$ & 1820 & $4.4 \times 10^{16}$ & 7792 \\
\hline
\end{tabular}

was $2 \mathrm{~mW}$ and the spot size was $250 \mu \mathrm{m}$. Table 1 gives an overview of the PL results.

Fig. 3 gives examples of the two types of spectra recorded. The $1.1 \mu \mathrm{m}$ InGaAsP grown at $580^{\circ} \mathrm{C}$, the $1.2 \mu \mathrm{m}$ InGaAsP grown at $555^{\circ} \mathrm{C}$, as well as the $1.4 \mu \mathrm{m}$ InGaAsP grown at $530^{\circ} \mathrm{C}$ all show a single peak. The $1.2 \mu \mathrm{m}$ InGaAsP grown at $530^{\circ} \mathrm{C}$ and the $1.1 \mu \mathrm{m} \mathrm{InGaAsP}$ grown at both $555^{\circ} \mathrm{C}$ and $530^{\circ} \mathrm{C}$ show multiple peaks consisting of a single broad peak (FWHM $\geq 20 \mathrm{meV}$ ) and one or two narrow peaks (FWHM $\leq 10 \mathrm{meV}$ ). It has been previously postulated that the broad PL peaks are due to compositional grading or alloy clustering [8]. Table 1 also lists the relative integrated intensities for each of the samples, including the contribution from all peaks. There is a clear increase in the PL signal level as the substrate temperature is increased from 530 to $555^{\circ} \mathrm{C}$, with a continuing increase in the $1.1 \mu \mathrm{m}$ In GaAsP PL signal level as the substrate temperature is increased further to $580^{\circ} \mathrm{C}$.

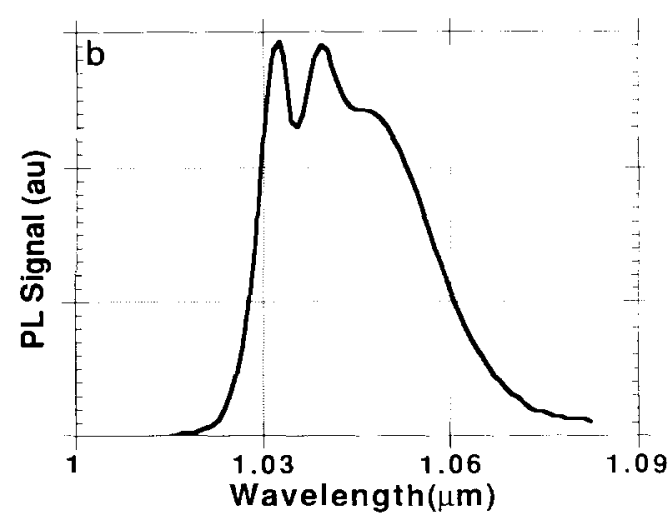

Fig. 3. (a) $7 \mathrm{~K}$ photoluminescence spectra of $1.1 \mu \mathrm{m}$ InGaAsP grown at $580^{\circ} \mathrm{C}$. (b) $7 \mathrm{~K}$ photoluminescence spectra of $1.1 \mu \mathrm{m}$ InGaAsP grown at $555^{\circ} \mathrm{C}$. 
InGaAsP at $1.1 \mu \mathrm{m}$ was grown on $\mathrm{InP}: \mathrm{Fe}$ substrates for Hall measurements at substrate temperatures of 540,555 and $580^{\circ} \mathrm{C}$. The layers were all $2-3 \mu \mathrm{m}$ thick. Table 2 gives a summary of the 300 and $77 \mathrm{~K}$ measurements. The three samples are comparable with only a small increase in the $77 \mathrm{~K}$ mobility for the sample grown at $555^{\circ} \mathrm{C}$.

Combining the results of the photoluminescence measurements and those of the mobility measurements, along with concerns about surface morphology, we have chosen $555^{\circ} \mathrm{C}$ as our optimum temperature for the growth of the quaternaries. From previous work [4], $555^{\circ} \mathrm{C}$ is definitely within the parameter window for the growth of the InGaAs active region quantum wells.

\section{MQW-SCH lasers}

Multi-quantum well separate confinement heterostructure lasers were grown to investigate the effects of strain on laser performance. The structure used is shown in the inset of fig. 4. The InP

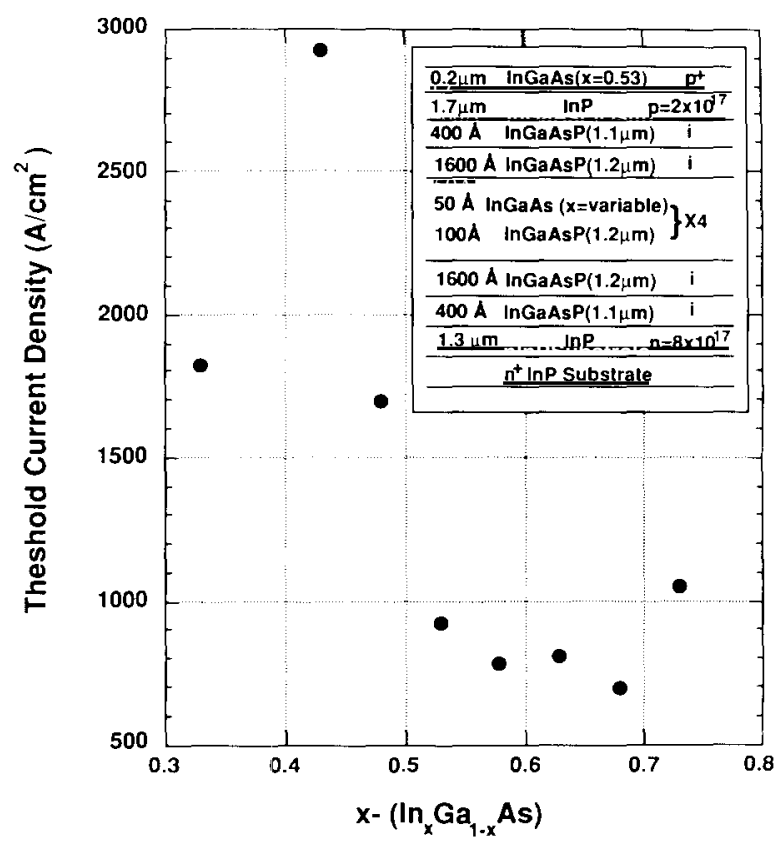

Fig. 4. Threshold current density for a MQW-SCH laser as function of indium composition in the InGaAs wells. cladding regions were grown at $580^{\circ} \mathrm{C}$, with the substrate temperature lowered to $555^{\circ} \mathrm{C}$ for the inner cladding and active regions. The lasers are broad area $(90 \times 800 \mu \mathrm{m})$ without any AR or HR coating, and were tested under pulsed conditions. For the laser grown with $x=0.33$, the $1.2 \mu \mathrm{m}$ InGaAsP was replaced with $1.1 \mu \mathrm{m}$ InGaAsP in order to maintain electron confinement.

Fig. 4 shows the variation in threshold current density as a function of indium concentration in the InGaAs quantum wells. The size of the quantum wells was held constant and therefore the lasing wavelength varied from $1.37 \mu \mathrm{m}$ at $x=0.43$ to $1.61 \mu \mathrm{m}$ at $x=0.63$. The best threshold current density is $689 \mathrm{~A} / \mathrm{cm}^{2}$ for $x=0.68$. The threshold current density is strongly dependent on the joint density of states (DOS) in the quantum well. As the composition of the InGaAs is altered, the heavy hole and light hole bands change position within the well. In the worst case $(x \sim 0.46)$ the heavy and light hole bands overlap, and the increased DOS causes a sharp increase in $J_{\text {th }}$. A more complete explanation is given in ref. [9]. The high quality of the InGaAsP is also demonstrated by the low loss coefficient of only $5.9 \mathrm{~cm}^{-1}$ measured for $x=0.58$.

\section{Conclusions}

InGaAsP at $1.1,1.2$ and $1.4 \mu \mathrm{m}$ has been grown by chemical beam epitaxy for use in MQW-SCH lasers. The TEG and TMI incorporation coefficients show strong temperature sensitivity between 530 and $580^{\circ} \mathrm{C}$, while the $\mathrm{PH}_{3}$ and $\mathrm{AsH}_{3}$ incorporation was constant over the same temperature range. Photoluminescence was used to measure the quality of the bulk InGaAsP and to identify regions of possible compositional grading. Finally, MQW-SCH lasers were produced with a best threshold current density of 689 A $/ \mathrm{cm}^{2}$ for $x=0.68$ for a broad area device.

\section{Acknowledgments}

The authors would like to thank Mr. Larry Davis for his assistance with the PL measure- 
ments. This work was supported by the US Army Research Office, URI Program, Contract DAAL03-86-K-0007.

\section{References}

[1] W.T. Tsang, M.C. Wu, T. Tanbun-Ek, R.A. Logan, S.N.G. Chu and A.M. Sergent, Appl. Phys. Letters 57 (1990) 2065.

[2] M.B. Panish, H. Temkin and S. Sumski, J. Vacuum Sci. Technol. B 3 (1985) 657.

[3] W.T. Tsang and E.F. Schubert, Appl. Phys. Letters 49 (1986) 220.
[4] M.E. Sherwin, G.O. Munns, M.E. Elta, E.G. Woelk, S.B. Crary, F.L. Terry and G.I. Haddad, J. Crystal Growth 111 (1991) 594.

[5] E. Woelk, M.E. Sherwin, G.O. Munns and G.I. Haddad, J. Crystal Growth 110 (1991) 452.

[6] N. Kobayashi, J.L. Benchimol, F. Alexandre and Y. Gao, Appl. Phys. Letters 51 (1987) 1907.

[7] J.Ch. Garcia, Ph. Maurel, Ph. Bove and J.P. Hirtz, J. Appl. Phys. 69 (1991) 3297.

[8] H. Temkin, V.G. Keramidas, M.A. Pollack and W.R. Wagner, J. Appl. Phys. 52 (1981) 1574.

[9] D. Nichols, M. Sherwin, G. Munns, J. Pamulapati, J. Loehr, J. Singh, P. Bhattacharya, M. Ludowise, E. Chan and R. Fu, in: Proc. 3rd Intern. Conf. on Indium Phosphide and Related Materials, April 1991, p. 146. 